\title{
COMMENT \\ Candida esophagitis in a male homosexual = AIDS?
}

\author{
A.B.R. THOMSON, MD, PHD, FRCP(C), FACP
}

\section{A} LMOST OVERNIGHT A NEW IMMUNOLOGICAL DISEASE HAS emerged in epidemic proportions. This devastating modern day plague, the acquired immune deficiency syndrome (AIDS), is characterised by a profound defect in immune function. Susceptibility to opportunistic infections is probably the cause of the alarmingly high fatality rate among AIDS sufferers. This susceptibility arises from a severe deficiency in cell-mediated immune function owing to the qualitative and quantitative depletion of helper/inducer T lymphocytes (T4).

The retrovirus of the human $T$ cell lymphotropic virus has been identified as the pathogenic agent in this disorder. The human immunodeficiency virus (HIV) binds to the surface of the $T$ cell and infects it, the cell then dies prematurely. The impaired function and gradual depletion of the T4 lymphocytes leads to the reversal of the helper/inducer:suppressor/ cytotoxic (T4:T8) cell ratio.

T4 lymphocytes are important in the induction of normal immune responses, including B cell associated immunoglobulin production and the recognition of antigens in the context of class II major histocompatibility complex products. B cell responses may be abnormal as may those of monocyte macrophages.

The anergy, neoplasm and increased susceptibility to opportunistic and other infections are central to the development of immunodeficiency and the clinical manifestations of AIDS.

Currently, most AIDS patients are from recognizable high risk groups; homosexuals, bisexuals, persons having a high number of sexual partners and those practising receptive anal intercourse, intravenous drug users, persons receiving whole blood or blood components before routine screening of donors and children born to HIV positive mothers. Standard precautions, similar to those used for preventing hepatitis B virus transmission, should protect health care workers and others in

Division of Gastroenterology, Department of Medicine, 519 Robert Newton Research Building. University of Alberta, Edmonton, Alberta T6G 2C2 contact with AIDS patients from becoming infected. It must be emphasised that, at present, being HIV positive is much more common than clinically detectable disease.

AIDS sufferers often present with gastrointestinal symptoms. Initially, the patient may have an acute viral illness lasting up to two weeks with symptoms including diarrhea, nausea, vomiting and anorexia. Diarrhea is also a late manifestation of the disease which is accompanied by substantial weight loss.

While there may be specific infecting agents, not all persons are found to be infected with an opportunistic or nonopportunistic organism such as protozoa (cryptosporidium, Entamoeba histolytica, Giardia lamblia, Isospora belli), viruses (cytomegalovirus, Herpes simplex), fungi (Candida albicans) or bacteria (Mycobacterium avium-intracellulare, Salmonella typhimurium).

In this edition (Page 33), Noble and co-workers from the University of British Columbia describe candida esophagitis in a male homosexual who did not have an underlying HIV infection. A specific but reversible impairment in neutrophil function was present which presumably resulted in defective candidacidal activity.

Did this patient have AIDS? The clinical presentation was consistent with recent criteria for definition of the disease but on two occasions, separated by six months, no HIV antibody was detected either by ELISA or Western blot technique. In addition the patient's OKT4:OKT8 lymphocyte ratio was nor$\mathrm{mal}$. Although there was a selective reduction in serum $\operatorname{lgG}$, no other common stigmata seen in chronic mucocutaneous candidiasis was present. There was no sign of hyperkeratosis or onychomycosis, no history of childhood recurrent infections or evidence for lymphocyte defect.

Two endoscopic studies, two and 12 months following antifungal therapy, revealed complete resolution of the candida esophagitis.

This case shows that clinical criteria alone should not be used to establish a diagnosis of AIDS, even in high risk patient populations. Alternative mechanisms for opportunistic infections in homosexual males should be explored in those patients who are HIV negative. 


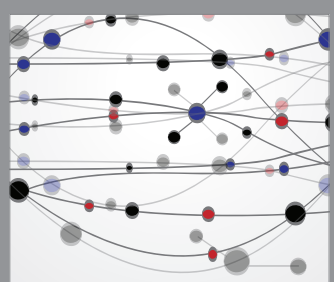

The Scientific World Journal


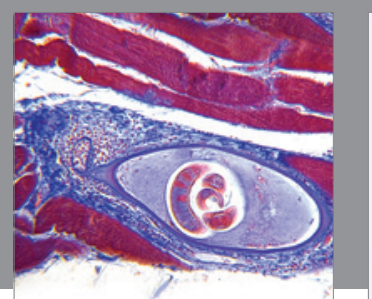

Gastroenterology Research and Practice

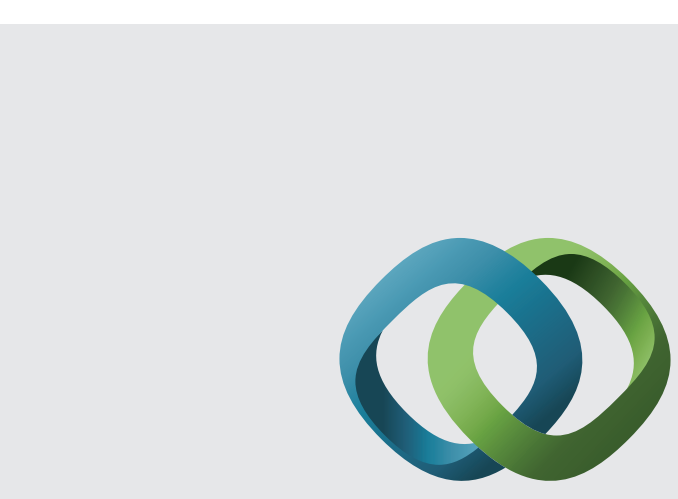

\section{Hindawi}

Submit your manuscripts at

http://www.hindawi.com
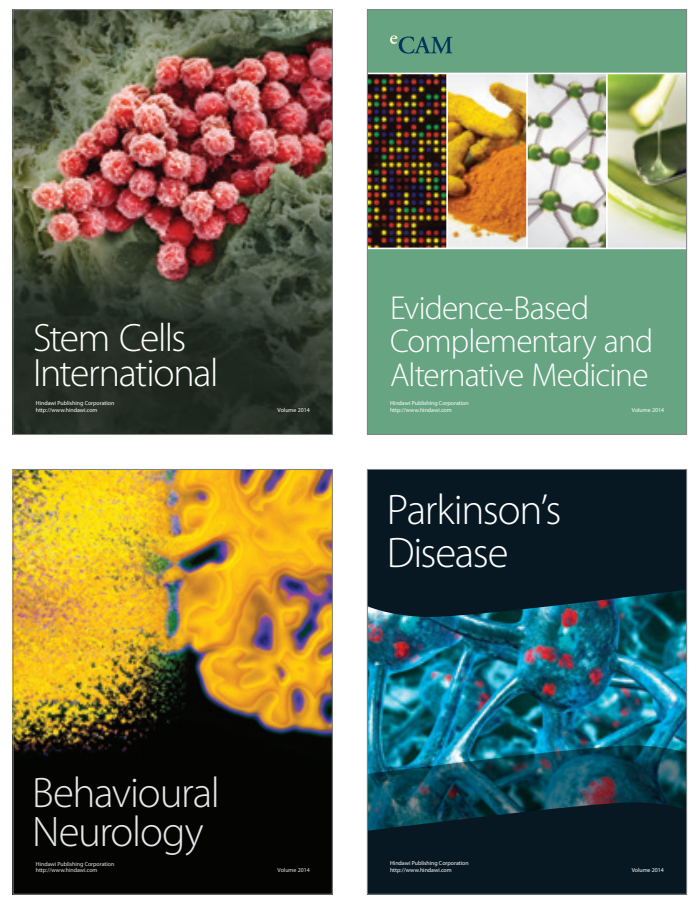
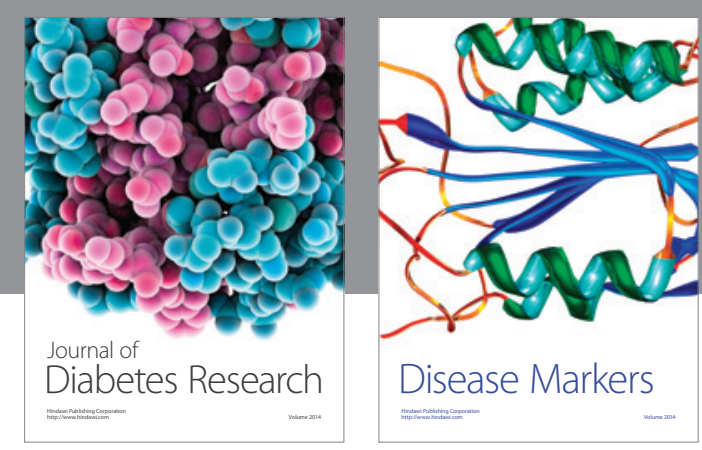

Disease Markers
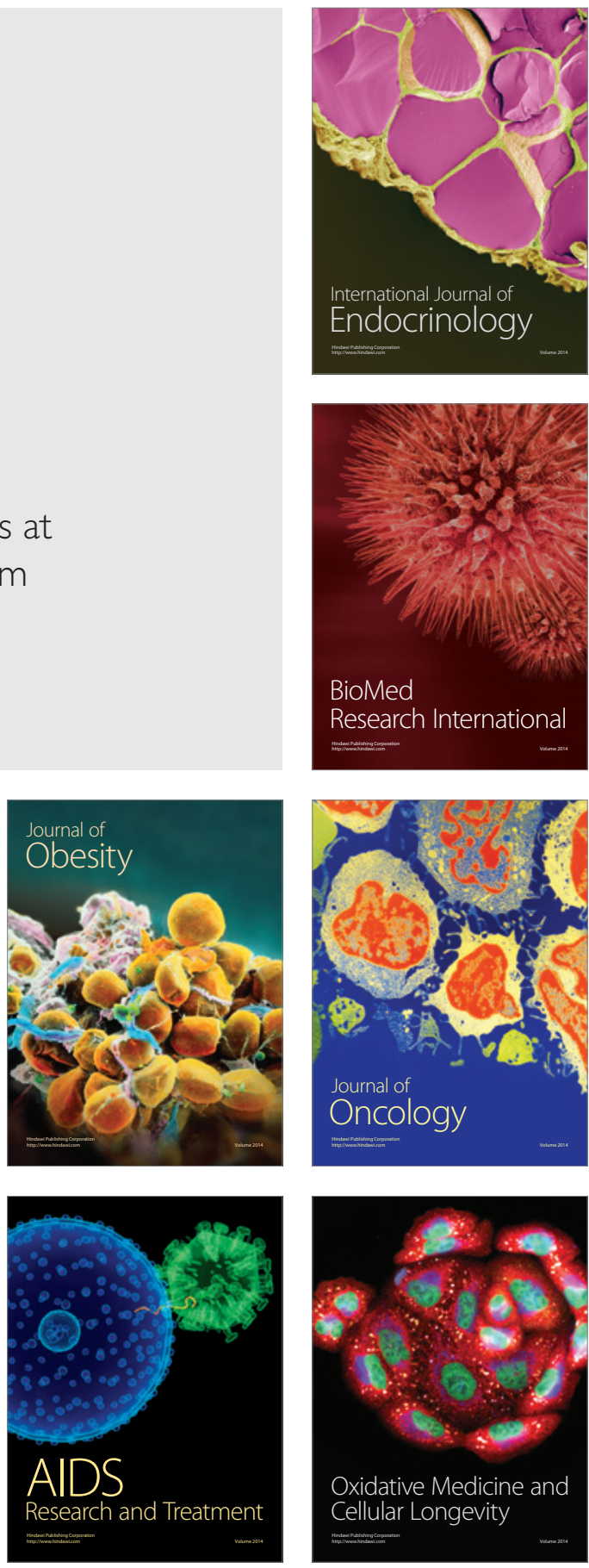